\title{
Origin and nature of coke in ethanol steam reforming and its role in deactivation of $\mathrm{Ni} / \mathrm{La}_{2} \mathrm{O}_{3}-\alpha \mathrm{Al}_{2} \mathrm{O}_{3}$ catalyst
}

Carolina Montero $^{a *}$, Aingeru Remiro $^{b}$, Beatriz Valle $^{b}$, Lide Oar-Arteta $^{b, c}$, Javier Bilbao $^{b}$, Ana G. Gayubo ${ }^{b}$

${ }^{a}$ Chemical Engineering Faculty, Central University of Ecuador, P.O. Box 17-01-3972. Ciudad Universitaria-Ritter s/n y Bolivia. Quito, Ecuador. Phone: +593 22544631. Fax: +59322529676

${ }^{b}$ Chemical Engineering Department, University of the Basque Country, P.O. Box 644, 48080. Bilbao, Spain. Phone: +34946 015361. Fax: +34946013500

${ }^{c}$ Catalysis Engineering / ChemE / TUDelft, Van der Maasweg 9, 2629 HZ Delft (The Netherlands)

*email: cdmontero@uce.edu.ec

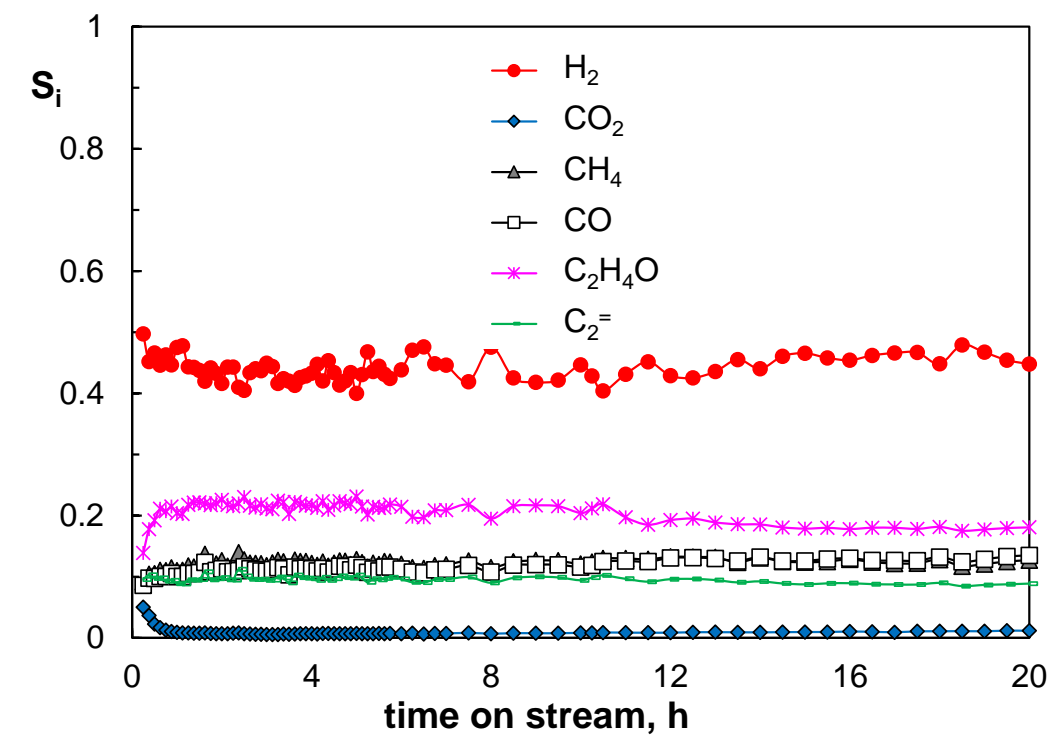

Figure S1. Evolution with time on stream of the selectivity of products in the SR of ethanol. Reaction conditions: $650^{\circ} \mathrm{C}, \mathrm{S} / \mathrm{E}=6$; space-time $=0.02 \mathrm{~g}_{\text {catalyst }} \mathrm{h} / \mathrm{g}_{\mathrm{EtOH}}$ 

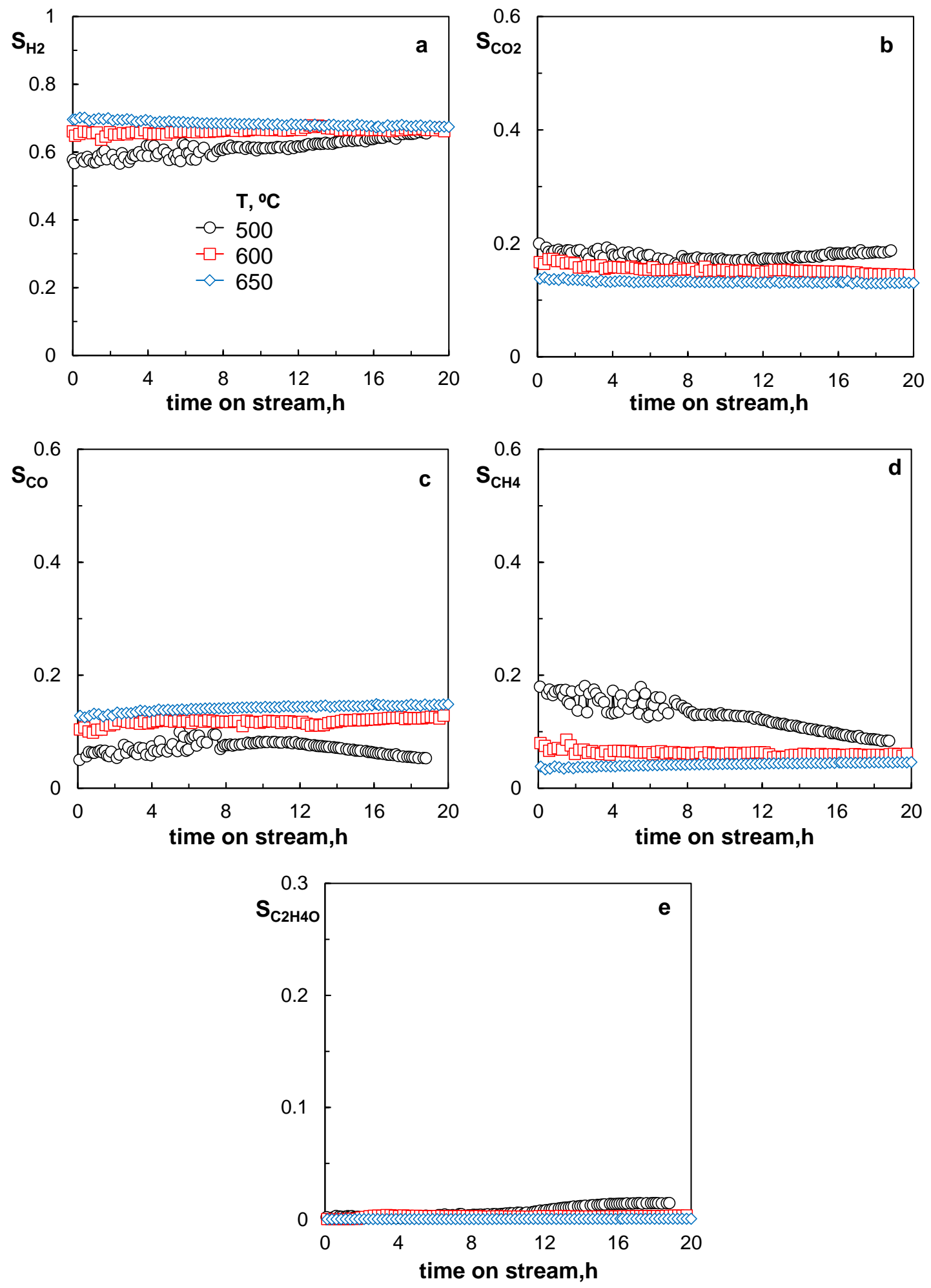

Figure S2. Effect of temperature on the evolution with time on stream of the selectivity of $\mathrm{H}_{2}$ (a); $\mathrm{CO}_{2}$ (b); $\mathrm{CO}$ (c); $\mathrm{CH}_{4}$ (d) and acetaldehyde (e). Reaction conditions: space-time; $0.18 \mathrm{~g}_{\text {catalyst }} \mathrm{h} / \mathrm{g}_{\mathrm{EtOH}} ; \mathrm{S} / \mathrm{E}=3$. 

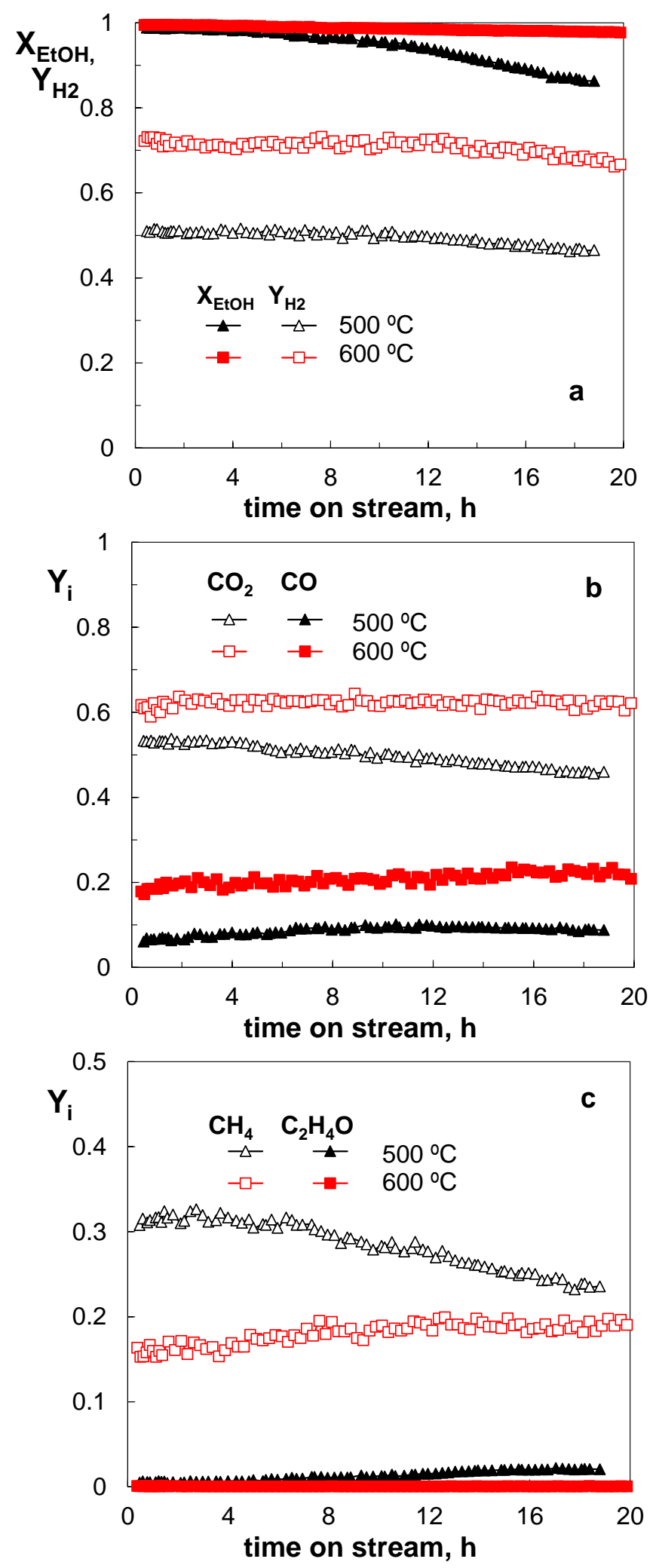

Figure S3. Effect of temperature on the evolution with time on stream of ethanol conversion and yield of $\mathrm{H}_{2}$ (a), yields of $\mathrm{CO}_{2}$ and $\mathrm{CO}$ (b) and yields of acetaldehyde and $\mathrm{CH}_{4}$ (c) in the SR of ethanol. Reaction conditions: $\mathrm{S} / \mathrm{E}=6$; space-time: $0.18 \mathrm{~g}_{\text {catalyst }} \mathrm{h} / \mathrm{g}_{\mathrm{EtOH}}$. 

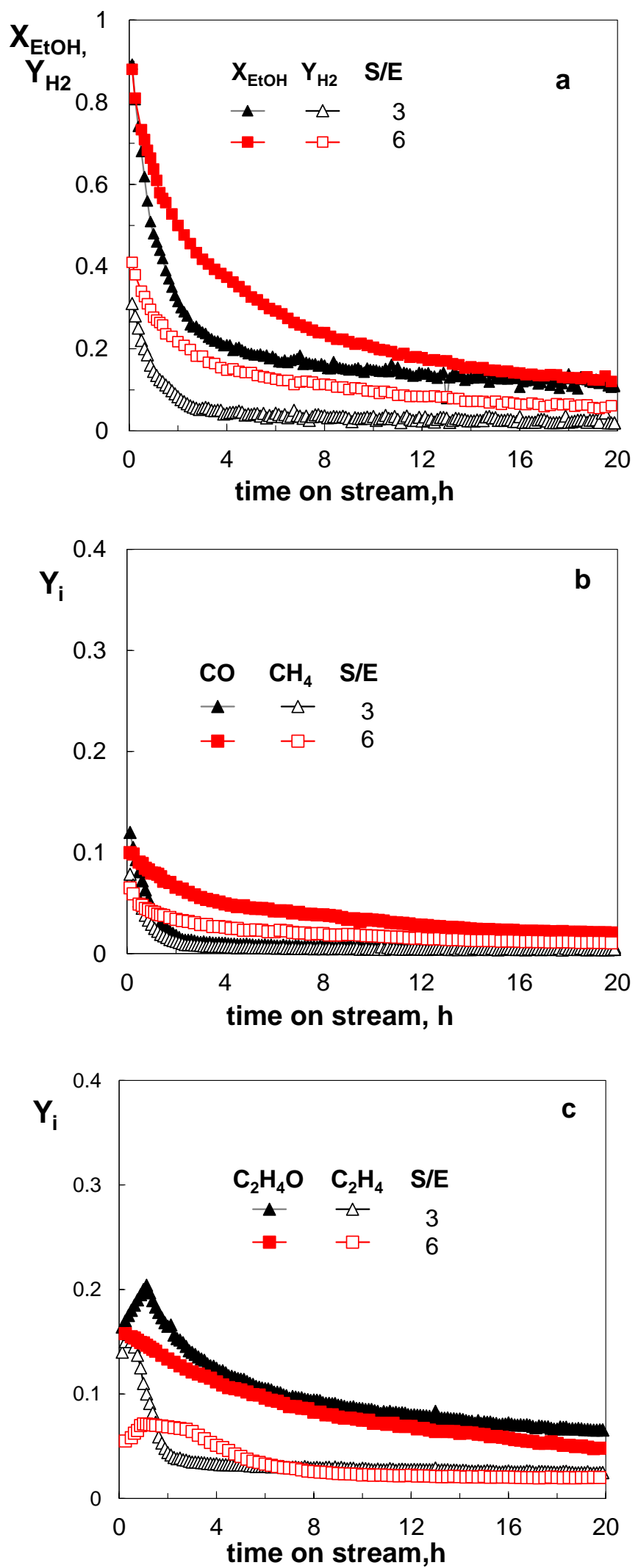

Figure S4. Effect of steam/ethanol molar ratio on the evolution with time on stream of ethanol conversion and yield of $\mathrm{H}_{2}$ (a), yields of $\mathrm{CO}_{2}$ and $\mathrm{CO}$ (b) and yields of acetaldehyde and $\mathrm{CH}_{4}$ (c) in the SR of ethanol. Reaction conditions: $600{ }^{\circ} \mathrm{C}$; spacetime: $0.04 \mathrm{~g}_{\text {catalyst }} \mathrm{h} / \mathrm{g}_{\mathrm{EtOH}}$. 

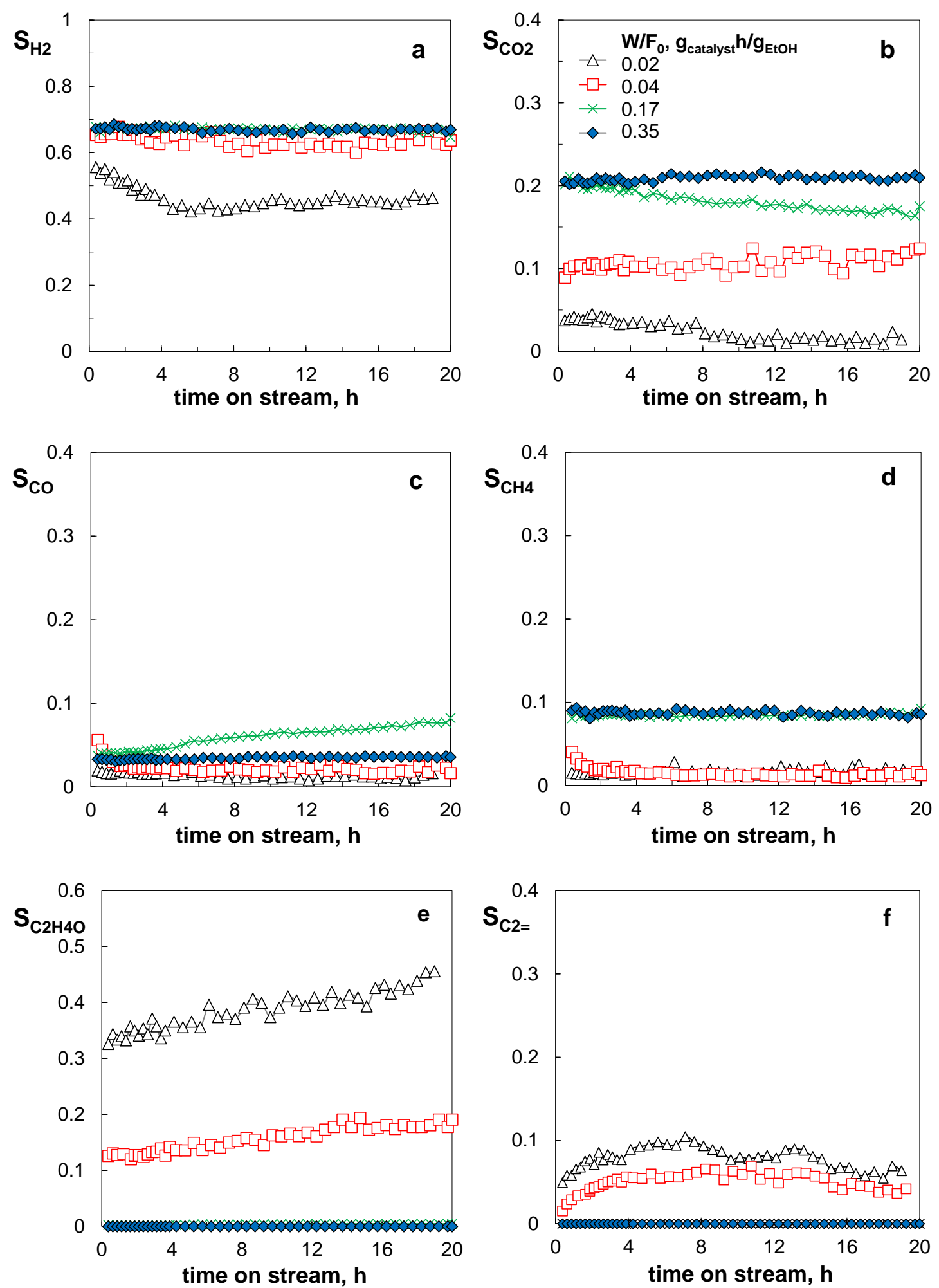

Figure S5. Effect of space-time on the evolution with time on stream of the selectivity of $\mathrm{H}_{2}$ (a); $\mathrm{CO}_{2}$ (b); $\mathrm{CO}$ (c); $\mathrm{CH}_{4}$ (d), acetaldehyde (e) and ethylene (f). Reaction conditions: space-time; $500{ }^{\circ} \mathrm{C}$, space time: $0.18 \mathrm{~g}_{\text {catalyst }} \mathrm{h} / \mathrm{g}_{\mathrm{EtOH}} ; \mathrm{S} / \mathrm{E}=3$. 

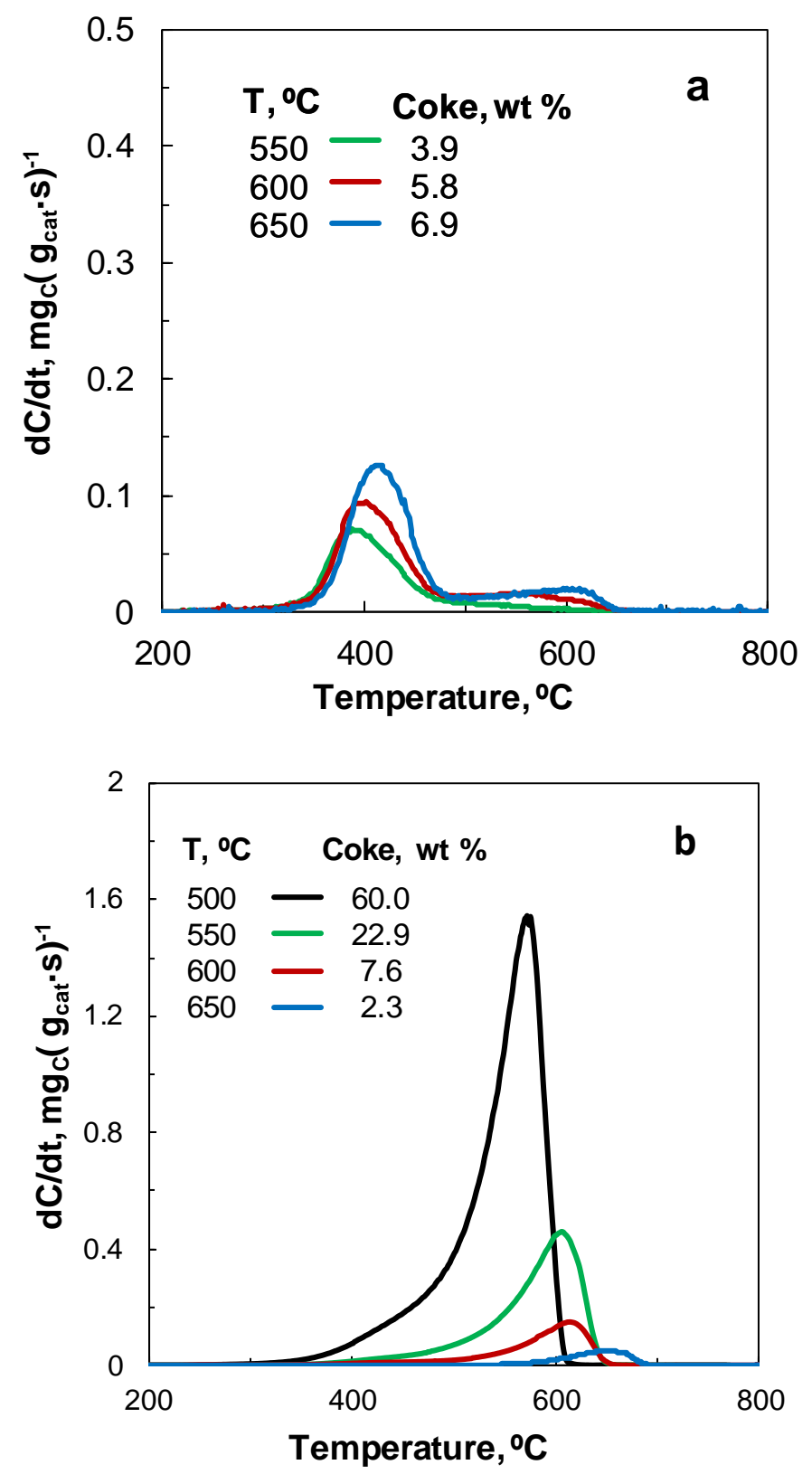

Figure S6. Effect of reaction temperature on the TPO profiles of deactivated catalyst. Reaction conditions: $\mathrm{S} / \mathrm{E}=3$; space-time: $0.04 \mathrm{~g}_{\text {catalyst }} \mathrm{h} / \mathrm{g}_{\mathrm{EtOH}}(\mathrm{a}) ; \mathrm{S} / \mathrm{E}=6$; spacetime: $0.18 \mathrm{~g}_{\text {catalyst }} \mathrm{h} / \mathrm{g}_{\mathrm{EtOH}}(\mathrm{b})$. 


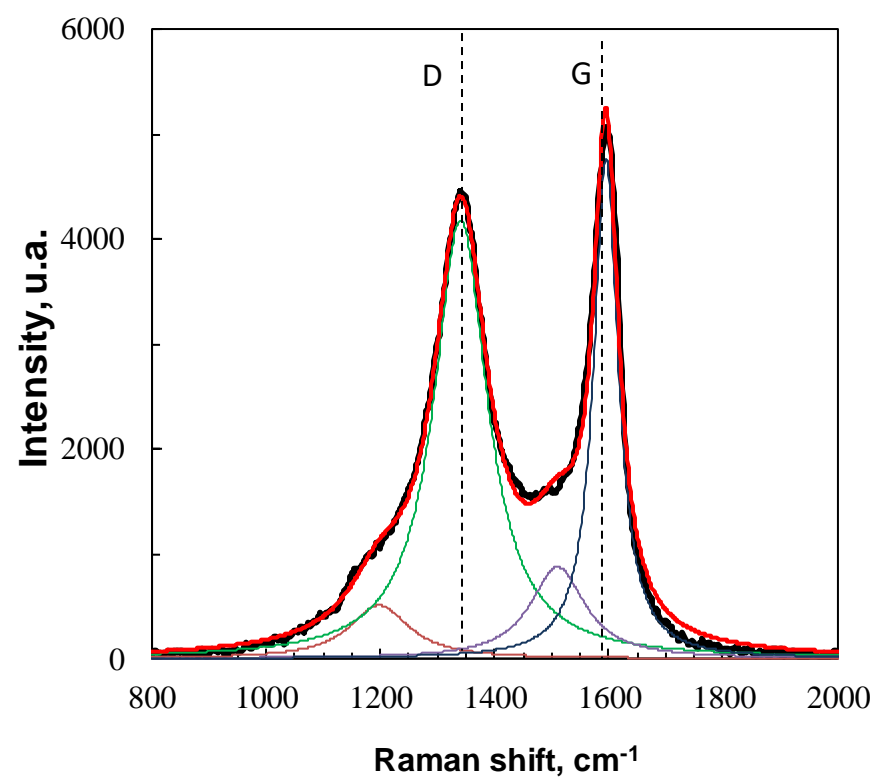

Figure S7. Deconvolution into four Lorentzian peaks of the Raman spectra (1800-1000 $\mathrm{cm}^{-1}$ region) of the catalyst deactivated at $500{ }^{\circ} \mathrm{C}$, with $\mathrm{S} / \mathrm{E}$ ratio of 6 and space-time of $0.35 \mathrm{~g}_{\text {catalyst }} \mathrm{h} / \mathrm{g}_{\text {EtOH}}$. 